\title{
Los derechos colectivos territoriales de los pueblos y nacionalidades indígenas en el arbitraje internacional de inversiones
}

Jaime Vintimilla

\section{Sumario}

1. Reflexión inicial. 2. Preocupaciones que se advierten en la realidad ecuatoriana por el arbitraje internacional de inversiones. 3. Los pueblos indígenas entre el ius cogens, el soft law y las inversiones. 4. La fragmentación del Derecho Internacional: una lucha entre el particularismo y el universalismo. 5. La interpretación de los instrumentos internacionales: Un todo integral o una fragmentación contextual. 6. Cortes locales y arbitraje. 7. Arbitraje Comercial internacional. 8. Arbitraje Internacional de Inversiones. 9. Conclusiones.

\section{REFLEXIÓN INICIAL}

En estudios distintos he analizado la titularidad de derechos que, gracias al reconocimiento de las normas constitucionales y de los instrumentos internacionales, poseen los pueblos indígenas. En la misma línea, también se ha advertido la existencia de impactos negativos generados por la industria extractiva en detrimento de la calidad de vida de los pueblos indígenas, ya que en ocasiones estas actividades han facilitado la vulneración de algunos de sus derechos colectivos.

Desafortunadamente, en la realidad constitucional local es frecuente que dicha violación de derechos nazca como consecuen- 
cia de decisiones estatales que han cedido, en contra de los estándares internacionales de Derechos Humanos, ante las necesidades económicas y políticas, lo que ha causado que los derechos colectivos pierdan fuerza y se relativicen.

En consecuencia, se advierte que los pueblos indígenas, a pesar de tener derechos reconocidos, sufren menoscabo en su ejercicio, en especial, cuando un conflicto ya sea con el estado, ya sea con las empresas es resuelto por los jueces nacionales con tesis alejadas del estado constitucional de derechos o sencillamente no se permite que los sujetos colectivos puedan ejercitarlos conforme la jurisprudencia vinculante de Derechos Humanos.

Esta situación acaece también cuando ciertos conflictos, donde están involucrados directa o indirectamente pueblos indígenas, llegan a foros internacionales distintos de los sistemas de protección de Derechos Humanos. En este sentido, merecen atención aquellos litigios arbitrales internacionales de inversiones donde no es todavía del todo clara la forma de reconocer y aplicar los textos normativos internacionales que garantizan sus derechos colectivos, pues en algunos casos se observa que dichos tribunales o instancias anacionales no han permitido una defensa adecuada de los Derechos Humanos e intereses de los pueblos indigenas.

\section{Preocupaciones que se advierten en la REALIDAD ECUATORIANA POR EL ARBITRAJE INTERNACIONAL DE INVERSIONES}

Ecuador es uno de los países que mantiene más juicios arbitrales de inversión y, a la vez, su carta constitucional es una de las que más protege a los derechos de los pueblos y nacionalidades indígenas. No obstante, existen algunas preocupaciones a causa de la apertura de nuevas opciones de explotación de recursos petroleros donde estos derechos han sido omitidos, dejando latente la posibilidad de juicios arbitrales internacionales, no ne- 
cesariamente de inversiones ante CIADI, ya que Ecuador denunció el convenio, pero sí ante otras sedes arbitrales.

En este sentido, la aprobación de la declaratoria de interés nacional que la Asamblea Nacional del Ecuador decretó en octubre de 2013 permite "la explotación de los Bloques 31 y 43, en una extensión no mayor al uno por mil $(1 / 1000)$ de la superficie actual del Parque Nacional Yasuni"1 ${ }^{\prime \prime}$.

La resolución legislativa hace posible la exploración y explotación de petróleo en una zona donde transitan pueblos indígenas no contactados. En consecuencia, el estado iniciará licitaciones petroleras para que empresas privadas y/o públicas puedan irrumpir en la vida de los pueblos indígenas que habitan allí.

Si bien la declaración de interés nacional busca también "garantizar los derechos de las personas, las colectividades y la naturaleza, para alcanzar el Buen Vivir o Sumak Kawsay", no es menor cierto que además existe un riesgo latente de declaratoria de responsabilidad internacional del estado ecuatoriano. Sin duda, la preocupación nace de la presencia futura y presente de empresas extractivas que si no consideran los derechos de los pueblos y nacionalidades indígenas generarán múltiples problemas ambientales, económicos y sociales, que algún momento deberán ser resueltos mediante distintos mecanismos de tutela judicial, arbitral o de otro tipo.

Lo alarmante del tema, es que ya existen antecedentes en laudos y decisiones arbitrales anteriores donde la posición adversa de los pueblos indígenas a la industria extractiva ha sido considerada como fuerza mayor y los árbitros se han inhibido de conocerla sin hacer un análisis, aunque sea somero, del Derecho Internacional ${ }^{2}$.

1. La declaratoria de interés nacional fuc aprobada por la Asamblea Nacional del Ecuador mediante Resolución legislativa publicada en el Registro Oficial Suplemento $106 \mathrm{de} 22$ de octubre de 2013.

2. Un cjemplo claro se puede advertir en la decisión sobre jurisdicción emitida por el tribunal arbitral conformado dentro del caso CIADI No. ARB/08/5 entre Burlington Resources Inc. y Ecuador. 
En general, no siempre de forma amigable, se encuentran dos visiones internacionales contrapuestas, ya que para los defensores de las inversiones empresariales podría parecer que los Derechos Humanos de los pueblos indígenas juegan un papel no más que secundario en la solución de los conflictos "inversionista estado" e incluso atentatorio a la globalización, aspecto que, en cambio, colisiona con aquella necesidad de establecer también la responsabilidad corporativa por las violaciones cometidas por las empresas o el mismo estado en contra de los pueblos y nacionalidades indígenas.

El principal problema que surge es el hecho que el estado, en no pocas ocasiones, vulnera el respeto de los Derechos Humanos e inclusive omite las normas constitucionales de los pueblos y nacionalidades indígenas cuando permite el desarrollo de actividades extractivas sin considerar la realidad socio-antropológica y jurídica de estos pueblos afectados con la extracción de recursos naturales.

Una de las consecuencias negativas de la imposición estatal es precisamente la generación del efecto de mantener invisibles a los pueblos indígenas en todos aquellos conflictos que el estado mantiene con las empresas extractivas, muy a pesar de que los indígenas claramente sufren diversos daños a su cultura, ataques a su autodeterminación, destrucción de su hábitat y forma de vida, contaminación de sus tierras, etc.

\section{LOS PUEBLOS INDÍGENAS ENTRE EL IUS COGENS, EL SOFT LAW Y LAS INVERSIONES}

Una de las mayores preocupaciones de los pueblos indígenas es, sin duda alguna, la falta de defensa adecuada de sus derechos colectivos, en especial los territoriales y los de autodeterminación, tanto en foros nacionales como en internacionales. Al respecto y si bien los sistemas internacionales de protección de Derechos Humanos han empezado a proteger a estos sujetos colectivos 
aplicando un nuevo ius gentium, más humanizado, que se basa más en la raison d'humanité que en la raison d'État, no obstante, todavía se advierte que en ciertos foros como el arbitraje internacional, los árbitros no aplican los instrumentos internacionales que defienden los derechos tanto de los pueblos indígenas en aislamiento voluntario que no tienen directo ius standi como de los pueblos indígenas en general, ya que supeditan sus derechos a los intereses del estado o a aquellos de los inversionistas, subsumiendo cualquier derecho colectivo en conceptos tan ambiguos como fuerza mayor ${ }^{3}$, expropiación indirecta o trato justo y equitativo.

$\mathrm{Al}$ respecto, es vital tener en mente que el Derecho Internacional de los Derechos Humanos es un sistema que tiene supremacía sobre cualquier otro derecho, más todavía cuando existe una marcada tendencia hacia la protección de lo que se considera grupos vulnerables. Así en el proceso de globalización en cual estamos inmersos aparecen diversos centros de decisiones, instancias de regulación, cortes internacionales donde los diversos actores (estados, empresas internacionales, instituciones financieras y comerciales internacionales, pueblos indígenas) tienen derechos y responsabilidades que son reguladas por distintas ramas del derecho internacional e instrumentos internacionales pero que se orientan no solamente a incentivar el libre comercio sino que buscan construir el desarrollo sostenible y la realización universal de los Derechos Humanos definidos en la Declaración de 1948 y en posteriores instrumentos internacionales.

Resulta vital, entonces, comprender que en la actualidad se acepta que varios agentes no estatales pueden también incurrir en violaciones de estos derechos y entre ellos encontramos a las Organizaciones Internacionales, las empresas multinacionales y

3. CANCado Trindade, A., International Law for Humankind: Towands a New Jus Gentium, The Hague Acadeny of International Law Monographs Martinus Nijhoft, 2010, p. 28. El autor intenta establecer un nuevo jus gentium que responda a las preocupaciones actuales de la humanidad, entre otras, la protección de derechos humanos, la autodeterminación de los pueblos, la protección ambiental, el desarrollo y cl desarme. Además manticne una fe enorme en el potencial del derecho para colmar las necesidades y aspiraciones de la humanidad como una herramienta totalmente opuesta al uso discrecional de la fuerza por parte de los estados. 
Los derechos colectivos territoriales de los pueblos y nacionalidades indigenas en el Arbitraje Internacional de inversiones

los grupos guerrilleros o terroristas. Es decir, "el Derecho Internacional de los Derechos Humanos no tiene por objeto imponer penas a las personas culpables de sus violaciones, sino amparar a las víctimas y disponer la reparación de los daños que les hayan sido causados por los estados responsables de tales acciones"4. En consecuencia, los pueblos indígenas deben ser resarcidos o indemnizados si han sufrido agresiones a sus Derechos Humanos por parte del estado y de las empresas en actividades de extracción.

En esta misma línea, las empresas no solamente se deben ajustar a los principios rectores de Ruggie sobre empresas y Derechos Humanos ${ }^{5}$, sino que tampoco pueden reducir las responsabilidades a buenas prícticas o peor aún, buscar que la llamada responsabilidad social corporativa $\mathrm{RSC}$, sea considerada únicamente como soft law; al contrario, urge mayor rigidez en el trato normativo, sometimiento a rendición de cuentas y a normas de transparencia más efectivas para reducir cualquier privilegio y a la vez diseñar mecanismos más eficientes de protección de Derechos Humanos que consideren las asimetrías de los pueblos indígenas ${ }^{6}$.

Por último, el dilema que se enfrenta en la realidad es considerar como distintos y paralelos a los sistemas de inversiones y de derechos humanos o comprender que el derecho internacional debe ser un referente para proteger a los diferentes sujetos y por ello no puede alejarse de la legislación internacional en materia de medio ambiente y derechos humanos ${ }^{7}$.

4. Faúndez Ledesma, H. El Sisfema Interamericano de Protección de los Denechos Humanos. Aspectos institucionales y procesales, tercera cdición, Instituto Interamericano de Derechos Humanos, San José, 2004 , pp. 11 y 12.

5. Documento de la ONU A/HRC/17/31 de 21 de marzo de 2011. Este informe fue preparado por John Ruggic, profesor de ciencias politicas en la Universidad de Harvard, asesor de Kofi Anan para la claboración del Pacto Mundial y de las Metas del Milenio, fue nombrado como representante especial del Secretario General para la cuestión de los derechos humanos y las empresas transnacionales y otras empresas comerciales. Al término de su mandato de tres años, en el año 2008, el Consejo de derechos humanos exiendió su mandato por tres años más, los cuales cuiminaron en junio de 2011 con la presentación de su informe final. En López Hurtado, C., "Empresas y derechos humanos: hacia el desartollo de un marco normativo internacional". Aportes DPLF, Empresas y derechos humanos: una relación compleja, número 15 , septiembre de 2011 , pp. 7 y 8.

6. HaLenZ1 MÉnDEZ, L., Süper derechos de inversiones vs endebles derechos humanos, América Latina en Movimiento ALA], 2013. Disponible en [hitp://es.justinvestment.org/2013/07/super-derechos-deinversiones-vs-endebles-derechos-humanos/], (Pảgina visitada el $18 \mathrm{de} \mathrm{junio} \mathrm{de} \mathrm{2014).}$ 


\section{LA FRAGMENTACIÓN DEL DERECHO INTERNACIONAL: UNA LUCHA ENTRE EL PARTICULARISMO $Y$ EL UNIVERSALISMO}

Uno de los grandes problemas que enfrenta la protección efectiva de los derechos colectivos de los pueblos indígenas es precisamente la denominada fragmentación ${ }^{8}$ del derecho internaciona $1^{9}$, pues se han ratificado varios instrumentos internacionales paralelos que muchas veces colisionan entre sí. En este sesgo, se advierte la coexistencia, no siempre pacífica, entre regímenes internacionales como el sistema internacional de comercio, de derechos humanos, de inversiones ${ }^{10}$, de medio ambiente, donde además cada uno presenta sus componentes sustantivos y sus mecanismos de solución de controversias ${ }^{11}$ así como se observa el aparecimiento progresivo y cada vez más sólido de otros sujetos internacionales como los individuos, los pueblos indígenas, organismos internacionales y empresas multinacionales que interactúan con los diversos estados.

8. La fragmentación del derecho internacional aparece por el surgimiento de reglas especializadas y autónomas, instituciones legales y órganos jurisdiccionales que resultan de la generación de distintas ramas de derecho intemacional especializadas y separadas entre si. Ver FaruQue, A., "Mapping the Relationship between Investment Protection and Human Rights", The Journal of Investments \& Trade, Vol. 11, No. 4, Auggust 2010.

9. Para ciertos autores las nuevas áreas del derecho internacional más importantes son dieciséis: Derecho internacional constitucional, detecho internacional administrativo, derecho penal, derecho laboral, de. recho del desarrollo, derecho internacional mercantil o comercial, derecho de los tratados, derecho de! mar, derecho internacional humanitario, teoria general de los derechos humanos o derecho internacional de los derechos humanos donde hay una rama especializada denominada derecho internacional de los pueblos indigenas, derecho intemacional fiscal, derecho intemacional del medio ambiente, derecho internacional aeronáutico, derecho intemacional nuclear, derecho espacial o cósmico, derecho de la integración o comunitario. Ver Valencia Restrepo, H., Derecho Internacional Público, $3^{2}$. cdición, Comlibros, Bogotá, 2008, p. 793.

10. Hoy en día el derecho internacional de las inversiones se caracteriza por la presencia de un sistema multifacético de reglas que, a su vez, constituye una fuente de complejidad, inconsistencia y desequilibrio. Los desafios consisten, entonces, en aumentar la transparencia, la coherencia y la certeza legal. Por ello, el escenario actual de este derecho se encuentra dominado por la presencia de varias disposiciones o cláusulas conienidas en instrumentos internacionales bilaterales, regionales, plurilaterales o multilaterales que versan sobre diversos aspectos relacionados con la inversión. Ver SAUvant, K., Ap̣peals Mechanism in International Investment Disputes, Oxford University Press, New York, 2008, p. 18.

11. Orellana, M., "Fragmentación y acumulación de regimenes internacionales: los derechos indigenas vis privilegios de los inversionistas", en Aylwin, J. editor, $1^{2}$. ed., Derechos humanos y puebles indigenas. Tendencias internacionales y contexto chileno, Instituto de Estudios indigenas/universidad de la Frontera, Temuco, 2004, p. 44. 
Este tema es crucial, pues no necesariamente los sujetos de derechos reconocidos en el plano interno, en especial en el constitucionalismo plurinacional, se proyectan de la misma forma y con la misma fuerza en la esfera internacional donde la defensa de sus derechos es todavía relativa y débil.

Esta situación grave genera indefectiblemente diversos conflictos relacionados con las inversiones, los mecanismos de solución de controversias o la aplicación normativa.

$\mathrm{Al}$ respecto, uno de los problemas más acuciantes es precisamente la relación, no siempre clara, entre el derecho de inversiones y el derecho internacional de los Derechos Humanos, pues se trata de un vínculo muy complejo y hasta controversial ${ }^{12}$, donde se muestran dos tendencias claramente determinadas ${ }^{13}$, más allá de los avances constitucionales de cartas constitucionales como la ecuatoriana donde no solo se han incorporado los Derechos Humanos sino que se ha dotado de subjetividad y acciones propias a los pueblos indígenas ${ }^{14}$.

Por otro lado, la fragmentación del Derecho Internacional enfrenta un nuevo debate en el sentido que esta realidad no impide que los órganos especializados de derecho internacional, e incluso sus normas, puedan interactuar sin generar necesariamente conflictos ${ }^{15}$, es decir, se enfrentan dos tesis con argumentos

12. TERAN, D., Human Rights and Investment Law. The role of human rights in investment arbitration, Universidad de Chile/Universidad de Heidelberg. Tesis de LL.M. int. International Investment Law, Investments, Trade and Arbitration, Santiago, 2011, p. 6.

13. Hay una tendencia positiva y optimista liderada por James FrY que considera que la protección a las inversiones y los derechos humanos son conceptos que se apoyan entre si y por ello pueden coexistir en plena armonia. Por otro lado, existe una tesis negativa y pesimista, pues algunos autores han argumentado que el arbitraje de inversiones imprime un impacto desfavorable en los derechos humanos y conduce a un conflicto entre estos dos sistemas de derecho intemacional. Ver Fry, J., "International Human Righis Law in Investment Arbitration: Evidence of Intermational Law's Unity", Duke Journal of Comparative \& International Law; Vol. 18:77, 2007.

14. Se habla de derecho constitucional de los derechos humanos a la incorporación de los principios universales de derechos humanos en las cartas latinoamericanas. Por eso FiX-Zaneudio indiea que los derechos que integran la que se podria denominar derecho constitucional de los derechos humanos, se han enriquecido con los establecidos en los instrumentos intemacionales ratificados por los gobiemos latinoamericanos, $y$ que constituyen el derecho internacional de los derechos humanos, estos ùltimos considerados como de naturaleza progresiva. Ver Fix-Zamudio, H. Los Derechos Humanos y su pmtección internacional, UNAM/GRIJLEY, Chiclayo, 2009, p. 15.

15. TERAN, D., Human Rights and Investment Law. The role of human nights in investment arbitration, p. 60. 
encontrados: los universalistas que defienden la unidad del derecho internacional y los particularistas que convergen en la fragmentación del derecho internacional.

En cuanto a la fragmentación, siguiendo a FRY, se subdivide en cuatro grupos: El primero advierte a la especialización creciente de la sociedad y el derecho como causa fundamental de la fragmentación que es asumida, de forma intrínseca, en el sistema contemporáneo. El segundo se basa en el aumento del número de actores dentro del ámbito internacional, aquí la fragmentación es generada por el hecho que todos presentan una visión u opinión jurídica distinta. El tercer grupo considera que el sistema legal internacional es fragmentado a causa de diversos factores como la proliferación de regulaciones internacionales, la mayor fragmentación política, la regionalización del derecho internacional, los nuevos sujetos de derecho internacional como las personas, y la especialización de las regulaciones internacionales. Por último, el cuarto grupo considera que la globalización y la pérdida de cierto poder local son causas fundamentales de la fragmentación ${ }^{16}$.

No obstante, al parecer la visión universalista es la más convincente, pues la fragmentación ignora el hecho que las cortes y los tribunales internacionales han empezado a confiar o depender espontáneamente de las normas y la jurisprudencia de otros regímenes especializados ${ }^{17}$, aunque también se advierte que los

16. Faruque, A., "Mapping the Relationship between Investment Prolection and Human Rights", The Journal of Investments \& Trade, Vol. 11, No. 4, August 2010, pp. 138-40.

17. Siguiendo a FRY hay tres razones especificas: En primer lugar, los tribunales y cortes intemacionales se mucstran fexibles en la redacción de sus resoluciones y, para ello, pueden considerar dentro de sus propios casos, las decisiones de otros foros para interpretar y aplicar los tratados relevantes, asi de este modo, los árbitros no deciden simplemente según el convenio o en base de un vacio legal. Particularmente en el caso del régimen internacional de inversiones y el sistema de derechos humanos, hay algunos casos en arbitraje de inversiones en los cuales los tribunales han confiado en la jurisprudencia de derechos humanos para formular decisiones claves. Al respecto, uno de los casos mis interesantes es Glamis Gold contra Estados Unidos de América donde la nacionalidad indigena Quechan remitio un amicus curiae argumentando que las disposiciones del NAFTA debcrian ser interpretadas de una forma concordante con las obligaciones internacionales de los tratados y el derecho consuctudinario que se orienten a proteger la tierra y los recursos de los pueblos indigenas. El tribunal arbitral desechó en su totalidad la pretensión de Glamis Gold y ordenó que la empresa pagara las dos terecras partes de los costos arbitrales. La segunda razón es la unidad inherenie del sistema legal inıernacional, dado que bajo el artículo 38 del estatuto de la Corte Internacional de Justicia los principios generales del derecho 
operadores jurídicos que tienen a su cargo la interpretación y aplicación de los tratados de inversiones usualmente no consideran, cuando deben decidir, las normas de otras ramas del derecho internacional.

\section{LA INTERPRETACIÓN DE LOS INSTRUMENTOS INTERNACIONALES: UN TODO INTEGRAL O UNA FRAGMENTACIÓN CONTEXTUAL}

Conforme se defienda el universalismo o el particularismo del Derecho Internacional, un grave problema que se debe abordar es la doble vara o doble rasero del estado, pues mientras por un lado reconoce ciertos derechos a sus ciudadanos como aquellos denominados colectivos, por otro lado, concluye acuerdos que los conculcan o, al menos, no los toman ni siquiera en cuenta para la negociación y ratificación de los instrumentos bilaterales o multilaterales que posteriormente deberán ser aplicadas por los tribunales arbitrales, dando como resultado el no respeto a esos derechos constitucionalmente reconocidos gracias a un manejo de instrumentos internacionales especializados que ignoran los Derechos Humanos.

Es por esto que las cláusulas de los tratados internacionales no pueden ser interpretadas arbitrariamente o en el vacío, ya que pertenecen al mismo ordenamiento jurídico internacional que debería ser considerado como un todo coherente e integral ${ }^{18}$.

Por esta razón, algunas universidades como la London School of Economics \& Political Science han gestado proyectos que buscan

son considerados como fuente del derecho internacional. Por consiguiente, lodos los sistemas legales tienen elementos comunes tales como pacta sunt servanda, bona fides, juicio justo, y nemo judex in re sua. En consecuencia, todos los regimenes especializados parecen estar rodeados por un derecho intemacional general. Por último, la existencia de superposiciones significativas entre diferentes órganos juridicos resulta innegable.

18. Dupuy, P., Petersmann, E., and Francion, F., "Human Rights in International Investment Law and Arbitration", Oxford: Oxford University Press, 2009. Oxford Scholurship Online.Oxford University Press. Disponible en [http://dx.doi.org/10.1093/acprof.0so/9780199578184.001 0001], (Pagina visitada el 1 de julio de 2014). 
urgentemente construir una conciencia mundial sobre la forma como las inversiones internacionales se procesan y como guardan relación con los impactos positivos y negativos que causan sobre los derechos humanos ${ }^{19}$.

En la realidad actual, empero, recientes cambios en la política global y en el entorno económico, incluyendo una serie de crisis en las finanzas, en la seguridad alimentaria y en el medio ambiente, han conducido hacia una nueva generación de políticas de inversión extranjera que colocan al crecimiento inclusivo y al desarrollo sostenible o sustentable en el corazón de los esfuerzos para atraer y beneficiarse de la inversión.

En el plano internacional y con más de 3200 acuerdos de inversión extranjera ${ }^{20}$, los desafíos para las políticas urgentes incluyen cuatro aspectos: a) Robustecimiento de la dimensión de desarrollo del régimen de políticas de inversión, b) Aseguramiento de espacios adecuados para las políticas a favor de los estados receptores de la inversión (host countries) mediante un equilibrio de intereses públicos y privados, c) Manejo de las serias deficiencias del sistema actual de resolución de conflictos inversionista-Estado, y d) Solución de aquellos aspectos que nacen de la complejidad creciente del régimen de políticas de inversión internacional ${ }^{21}$.

19. La idea es además crear espacios constructivos para el aprendizaje, la investigación, el debate y el intercambio de herramientas prácticas en las áreas de inversión y derechos humanos con la formación e intervención de la sociedad civil, ręresentantes gubernamentales, profesionales y grupos relevantes. El proyecto es una iniciativa del "laboratorio para la iavestigación avanzada sobre cconomia global" y es ejecutado por el centro de estudio de los derechos humanos de la London School y se denomina proyecto de derechos humanos $\mathrm{c}$ inversión (The Investment \& Human Rights Project). En abril de 2014 se presentó el centro o huh de aprendizaje de derechos humanos y derecho de inversiones que es un espacio virtual creado para construir una opinión sabre la inversión, los derechos humanos y su conexión. Este centro explora las implicaciones que estas conexiones tienen para el trabajo de los gobiernos, de los profesionales, inversionistas y miembros de la socicdad civil en el aseguramiento de la protección y respeto de los derechos humanos. Ver [http://blogs lse.ac.uk/investment-and-humanrights/]. (Consulta realizada el 1 de julio de 2014).

20. International investment agreements (IIAs), Ver United Nations Conferenec On Trade and Development UNCTAD, Investor-State Dispute Settlement, UNCTAD Series on Issues in International livestment Agreements II, United Nations, New York/Geneva, 2014.

21. Estos desafios podrian ser resueltos mediante esfuerzos coordinados. Para ello, ta última experiencia de la UNCTAD expresada en su "Invesment Policy Framework for sustainable development" (Marco de politicas de inversión para el desarrollo sostenible) puede servir como base para futuras construcciones de consenso sobre las politicas de inversión extranjera. Ver Towards a new generation of international investment policies: UNCTAD's fresh approach to multilateral investment policy-making. 
Los derechos colectivos territoriales de los puebios y nacionalidades indigenas en el Arbitraje interincional de inversiones

En esta misma línea, ha existido también un involucramiento del sector privado o empresarial en el quehacer público frente a la sociedad, y en especial frente a los Derechos Humanos, para posteriormente enfocarse en una revisión del régimen de responsabilidad internacional por violaciones a los Derechos Huma$\operatorname{nos}^{22}$. La idea ha sido coordinar o generar vasos comunicantes que consideren la diferencia determinante que existe, pues mientras los Derechos Humanos se basan esencialmente en la dignidad de la personas, el Derecho Internacional de las Inversiones se fundamenta en la protección de la inversión, y específicamente de los intereses del inversionista ${ }^{23}$.

A más del denominado Pacto Global de las Naciones Unidas existen iniciativas privadas como la Global Business Iniciative on Human Rights (GBI) que fue presentada en el año 2009 con el objetivo de promover y defender los Derechos Humanos en el contexto empresarial mundial ${ }^{24}$. Es decir, la inclusión de la defensa de los Derechos Humanos de los pueblos indígenas ya no es solamente un deber de los estados sino que paulatinamente se ha transformado en una obligación voluntaria de las empresas, más todavía cuando en el mundo existe la tendencia de la constitucionalización del derecho privado y el surgimiento, como ya se ad-

Updated in light of the world investment report 2013, IIA issues note, No. 5, july 2013. Disponible en [htip://unctad.org/en/PublicationsLibrary/webdiacpeb2013d6_en.pdf], (Consulta realizada el I de julio de 2014),

22. Tangarifc-Pedraza, M., "De la responsabilidad de la empresa y los derechos humanos", Revista colombiana de derecho internacional, Edición especial, No.12, 2008, p. 145.

23. OLARTE BACARES, D., El Derecho internacional de has inversiones en América Latina: El reencuentro con los derechos humanos, disponible en [http://lasil-sladi.org/files/live/sites/lasilsladi/files/shared/El $\% 20$ derecho $\% 20$ internacional $\% 20$ dc $\% 20$ las $\% 20$ inversiones $\% 20 \mathrm{cn} \% 20$ Am $\%$ C3 $\%$ A9rica\%20latina \%20su\%20rencuentro\%20con\%20los\%20dercehos\%20humanos pdf], (Visita realizada el I de julio de 2014).

24. The Global Business Initiative on Human Rights (GBl) exists to advane human rights in a business context around the world. The underlying vision is a global community of corporations from all sectors knowing and showing that they respect the dignity and rights of the people they impact and interact with. From a business perspective this supports an enhanced approach to giobal leadership and risk management, and can provide access to markets, customers and capital. GBI is led by a core group of 18 major comorations headquartered in Asia, Europe, Latin America, Middle East, North Africa and North America. The GBI work plan is organised into two paraltel tracks: First, Member Peer Learning creates a safe space for the $18 \mathrm{GBI}$ companies to share practices, challenges and innovations with peers focused on respecting human rights in practice and implementation of the UN Guiding Principles for Business and Human Rights. Second, Global Business Outreach focuses on awareness-raising and capacity building for business in diverse regions of the world, particularly in emerging and developing markets. Ver [http://www.global-business-initiative.org/], (página visitada el i de julio de 2014). 
virtió, de muchos sujetos internacionales del derecho que van más allá de los tradicionales estados, donde las personas y pueblos y nacionalidades indígenas no son solamente titulares de los derechos garantizados en las constituciones sino que pueden reclamar el cumplimiento de los instrumentos internacionales tanto a los estados como a las empresas extractivistas.

En otras palabras, se advierte que existe una influencia del nuevo modelo de derecho constitucional que busca ya no solamente controlar el poder desmedido del estado sino que ahora se proyecta al control de todo poder, inclusive privado, que pueda causar menoscabo a los Derechos Humanos e incluso generar indefensión. En este sentido, vale la pena citar al jurista italiano Luigi Ferrajoli ${ }^{25}$, quien al teorizar sobre el nuevo esquema constitucional surgido en las constituciones de postguerra, ha denominado constitucionalismo privado al proceso de constitucionalización del derecho privado. El autor inicia un largo desarrollo de los derechos fundamentales y su relación con el poder público y los poderes privados para llegar a una conclusión: la necesidad de constitucionalizar el derecho privado con el fin de precautelar derechos fundamentales de los individuos y colectivos en las relaciones de poder que allí se dan.

A su vez, la misma tendencia se advierte surgir en el ámbito del arbitraje internacional de inversiones donde se reclama un reequilibrio del régimen de inversiones similar a la constitucionalización que parece tomar cuerpo en el campo del derecho privado, tal es el caso de los códigos societarios ${ }^{26}$.

En definitiva, cuando se habla de constitucionalización se refiere a una suerte de irradiación de valores y principios que contenidos en la Carta Magna se mueven hacia diversos ámbitos del derecho, llegando incluso a invadir el derecho privado y el mismo

25. Ferrnjolı, L., La 'democracia cisil: Para un constitucionalisno de derecho privado. Principia Iuris. Teoria del Derecho y de la democracia: Parte VI. Trotta, Madrid, 2011, pp. 218-249.

26. MUIR WATT, H., The contested legitimacy of investment arbitration and human rights ordeal, Sciences Po Paris, Low School, 2014, pp. 19 y 20. Disponible en:

[http://halshs.archives-ouvertes.fr/does/00/97/29/76/PDF/hmw-investment-arbitration-and-humanrights.pdf], (Página visitada el 2 de julio de 2014). 
derecho internacional donde empiezan a aparecer conceptos clave que deben ser respetados tanto por los estados como por las empresas.

En este contexto, vamos a analizar si el arbitraje internacional de inversiones es un mecanismo eficiente que debe necesariamente defender los derechos de los pueblos indígenas, en especial, cuando se relacionan con la vulneración de sus derechos territoriales así como con los daños producidos por la industria extractiva o sencillamente este particular constituye un tema de justicia local o es exclusivo de los sistemas de defensa de Derechos Humanos.

\section{CORTES locales Y ARBITRAJE}

A menudo y de forma explícita los acuerdos de inversión extranjera incluyen a los jueces locales como una de las opciones para resolver los conflictos o controversias que puedan surgir entre los inversionistas y los estados (investor-state), incluso si en los acuerdos se guardara silencio, los jueces locales normalmente serían competentes para resolver estas disputas, aunque el reclamo del inversionista debería estar basado en el derecho local más que en la presunta violación de un acuerdo de inversión extranjera.

Por otro lado, algunos inversionistas bien podrían mirar a los procedimientos judiciales seguidos en los estados receptores de la inversión como indeseables o inútiles. Por ello, frecuentemente los acuerdos de inversión extranjera intentan mantener el equilibrio entre estos intereses incompatibles.

En todo caso, en muchos $\mathrm{AIE}^{27}$ se condicionaba el derecho del inversor para acceder al arbitraje internacional previo el agotamiento $^{28}$ de ciertos requisitos relacionados con la justicia local

27. Un ejemplo se puede advertir en el articulo 10 del TBI suscrito entre Argentina y Alemania. 
o doméstica, tales como: recursos vinculantes en la jurisdicción nacional dentro del host state, cláusulas disyuntivas, de elección de vías o de bifurcación de vías "fork in the road" y cláusulas de renuncia o no retorno "no-U-turn" o "waiver clauses" 29 .

Es decir, existen dos realidades que pueden denominarse complementarias, pues el inversor tiene en los países de recepción de la inversión, dependiendo del AIE, tanto la posibilidad de agotar todas las vias internas, judiciales y administrativas, antes de proceder con su reclamo en el nivel internacional como también tiene la opción de prevenir la duplicación de sus reclamos gracias a las cláusulas disyuntivas y de renuncia. Las primeras permiten que desde el inicio los inversionistas puedan escoger entre las cortes locales y el arbitraje internacional, pero una vez que se ha iniciado un procedimiento local se pierde el derecho de recurrir al arbitraje y viceversa. Las cláusulas de renuncia, en cambio, permiten a los inversores que opten por el arbitraje internacional después de haber incoado un reclamo ante jueces nacionales, empero, si bajo las cláusulas de arreglo de diferencias inversor estado contenidas en un AIE, el inversionista decide remitir dicho reclamo a arbitraje internacional, entonces, debe renunciar a su derecho de perseguir recursos locales.

En definitiva, nos hallamos ante una multiplicidad de foros potencialmente competentes para conocer una determinada divergencia relacionada con inversiones y debe precisarse que tienen su origen tanto en la legislación interna como en los tratados y estipulaciones contractuales ${ }^{30}$.

28. Este requisito de agotamiento de recursos intemos ha sido prácticamente eliminado de las disposiciones sobre solución de controversias en las Tralados bilaterales de inversión (TBI's). No es necesario el agotamiento de los recursos internos salvo estipulación en contsario, empero, conforme la segunda parte del articulo 26 del Convenio CIADI dispone que "un estado contratante podrá exigir cl agolamiento previo de sus vías administrativas o judiciales, como condición a su consentimiento al arbatraje conforme a este convenio". Ver Galindo, A., Iuris Dictio, "El Consentimiento en el Arbitraje Interna. cional en materia de inversiones", Año VII, No. 11, octubre 2007, p. 44.

29. United Nations Conference On Trade and Development UNCTAD, Investor-State Dispute Settlement. UNCTAD Series on Issnes in International Imestment fyreements 11 , pp. 79 a 90.

30. En lo estrictamente juridico, tres factores contribuyen a la distinción entre acciones basaclas en un tra. tado y acciones basadas en un contrato, a saber: a) Fuente de la acción donde la violación de un derecho consagrado en un tratado genera la responsabilidad internacional del estado receptor, mientras que un incumplimiento contractual origina la responsabilidad del estado receptor de acuerdo con su propia 
El problema estriba en la aplicación de las normas de Derechos Humanos como aquellas que defienden el respeto de los derechos de los pueblos indígenas, en especial cuando los estados han autorizado concesiones petroleras o mineras sin observar sus derechos así como cuando las empresas han suscrito contratos con conocimiento de causa de esta realidad adversa al derecho.

En el caso ecuatoriano, estos AIE no han considerado la realidad constitucional donde los pueblos indígenas han sido sujetos de derechos colectivos desde 1998 y por ello se ha generado un desequilibrio entre la letra o contenido constitucional y su proyección en el terreno internacional. A mi juicio además esta realidad se ha complicado aún más gracias a la debilidad judicial local que no ha sido capaz de defender los derechos constitucionales de los pueblos indígenas en temas controversiales como el caso de la declaratoria de interés nacional para la explotación del parque Yasuní, aspecto que ha hecho que ciertas leyes y contratos puedan aprobarse y suscribirse respectivamente sin la intervención de los pueblos indígenas afectando así sus derechos y exponiéndoles a arbitrajes internacionales donde a más de la escasa importancia dada al tema de sus Derechos Humanos, han sido ignorados ya que estos contenciosos consideran únicamente a los estados y a los inversionistas.

\section{Arbitraje Comercial InTERNACIONAL}

El arbitraje internacional se establece para solventar controversias derivadas de relaciones económicas internacionales ${ }^{31} \mathrm{y}$ es usado para marcar la diferencia entre los arbitrajes que son

legislación, b) Contenido del derecho subjetivo, pues un derecho ya reconocido por el tratado puede set posteriomente incluido y ampliado o delimitado en un contrato de inversión, y c) Derecho aplicable así el régimen jurídico aplicable a una acción basada en un tratado incluye las disposiciones de los AIE, la legislación interna del estado receptor y el derecho internacional generai, en cambio, los contratos de inversión estan regidos exclusivamente por el sistema legal del estado receptor, particularmente por las disposiciones que regulan los coniratos administrativos. Ver Morales Vela, D, "Arbitraje Internacional de Inversiones: Conflictos en la Aplicación de Cláusulas paraguas", luris Dictio, Año VII, No. I1, octubrc 2007, pp. 51 y 52.

31. Chilleón Medina. J., y Merino Mercilin, J., Tratado de arbitraje privado interno e internacional, segunda edición, Civitas, Madrid, 1991, p. 384. 
puramente nacionales o domésticos de aquellos que de alguna manera trascienden los límites nacionales y se convierten en internacionales o transnacionales ${ }^{32}$.

En este sentido y más allá del hecho cierto que en la actualidad mundial existe una tendencia marcada para pactar convenios arbitrales, no hacer huelga la diferencia entre el arbitraje comercial internacional y el arbitraje internacional de inversiones, pues a más de ser de diferente naturaleza presentan actores distintos en su escenario procesal. En concreto, el arbitraje comercial internacional es aquel que se concentra en la resolución de conflictos que guardan relación con contratos comerciales. La importancia de determinar el carácter comercial de una disputa radica que en algunas legislaciones el arbitraje internacional está limitado a disputas comerciales, lo que se entiende como la "reserva comercial" ${ }^{\prime \prime 3}$.

Al respecto, diversas legislaciones establecieron ciertas condiciones o criterios que sirven precisamente para determinar y conocer cuando existe un arbitraje internacional y para ello se ha recibido la influencia directa de la Ley Modelo ${ }^{34}$ de la CNUDMI de 1985 sobre arbitraje comercial internacional ${ }^{35}$.

Así, verbi gratia, en las legislaciones de España ${ }^{36}$ y Ecuador ${ }^{37}$ se ofrecen varias alternativas que determinan la calificación de un arbitraje como internacional y entre estos criterios, condiciones

32. REDFtr, A., y HUNTER, M., Law and Practice of International Commencial arbitration, third cdition, Sweet \& Maxwell, London, 1999, p. 12.

33. Fierro VAlle, E.. Conflicto objetivo de intereses en el arbitraje internacional: El fenómeno del "double-hatting", Tesis de grado, Universidad San Francisco de Quito, Colegio de Jurisprudencia, Quito, 2013, p. 52.

34. La Ley Modelo de la CNUDMI sobre arbitraje comercial internacional de 1985 , cueata con enmiendas adoptadas en 2006 y está formulada para ayudar a los cstados a reformar y modernizar sus leyes sobre el procedimiento arbitral a fin de que tengan en cuenta los rasgos peculiares y las necesidades del arbitraje comercial intemacional. Ver:

[http://www.uncitral.org/uncitral/es/uncitral_texts/arbitration/1985Model_arbitration.html], (Página visitada el 10 de julio de 2014).

35. Esplugues Mot^, C., "Sobre algunos desartollos recientes del arbitraje comercial intemacional en Europa", en Barona Vilar, S. Directora, Arbitraje y Justicia en el siglo. LXI, Thomson/Civitas, Pamplona, 2007, p. 179.

36. Articulo 3 de la Ley de Arbitraje.

37. Articulos 41 y 42 de la Ley de Arbitraje y Mediación. 
o requisitos se encuentran tres niveles: espacial, territorial y económico.

Por ello, en el contexto de un arbitraje comercial internacional se podría concluir que hay dos criterios relevantes que se usan indistintamente para calificarlo como tal: a) la naturaleza de la disputa, en especial, si involucra la defensa de intereses dentro del comercio internacional, y b) la situación de las partes, sobre todo, su nacionalidad o el lugar habitual de su residencia y en el caso de empresas el lugar de su administración y control ${ }^{38}$.

Como se sabe el arbitraje es un mecanismo alternativo de solución de controversias ${ }^{39}$ y más que alternativo es adecuado, ya por su autonomía, ya porque se lo debe utilizar como una herramienta especializada para ciertos casos, es decir, se debe analizar, caso por caso, para advertir si el arbitraje es o no conveniente para resolver los conflictos en juego.

El arbitraje, en clara oposición al proceso judicial, es un modo privado de solucionar los litigios ${ }^{40}$. Es decir, es privado porque nace de la autonomía de las partes, ya que pactan en un convenio arbitral la decisión de someterse a arbitraje para resolver sus diferencias y además porque se excluye a la justicia ordinaria de intervenir en estos casos.

En este sentido, el arbitraje internacional es un mecanismo extrajudicial y alternativo de resolución de conflictos contractuales, pactado por las partes, en el que está presente al menos un elemento que rebasa las fronteras de un país, que consiste en la definición de la controversia por parte de uno o varios árbitros que profieren un laudot1.

38. Rnpfenn, A., y Hunter, M., Law and Practice of International Commercial arbitration, p. 14.

39. Salcedo Verduga, E., El Arbitraje. La Justicia alternativa, segunda cdición actualizada, Distrilib, Guayaquil, 2007, p. 15.

40. LALIVE, P. "L'arbitrage international", en Répertoire de droit in ternational privé, 1" 82, Suisse, p. 241.

41. Botero Sanclemente, A., y Correa Henao, N., Arbitramento Imernacional, Cámara de Comertio de Bogotá. Bogotá, 2002, p. 13. 
Además su uso tiene varias ventajas que lo hacen atractivo, así permite que las partes encuentren protagonismo para participar en la selección del tribunal arbitral que estará conformado por expertos en disciplinas relevantes, luego el hecho que las disputas se desarrollen en territorio neutral y no en las sedes judiciales de una u otra parte le otorgan mayor confiabilidad, a lo que habría que sumar su flexibilidad procesal, pues puede adaptarse al contexto casuístico ${ }^{42}$ y a normas deslocalizadas o a-nacionales ${ }^{43}$.

Sin embargo, la internacionalización y la globalización de la economía que han llevado a los diferentes agentes comerciales a buscar métodos alternativos de resolución de controversias que respondan a la necesidad de otorgarles seguridad jurídica y rapidez a las transacciones ${ }^{4+4}$ encuentran un mundo más complejo cuando se trata de incluir a las inversiones extranjeras, a los estados y a los Derechos Humanos bajo un mismo parasol que se ha denominado Derecho Internacional de las Inversiones Extranje$\operatorname{ras}^{45}$.

\section{Arbitraje Internacional de InVersiones}

Como ya se advirtió ut supra, actualmente los países no pueden subsistir solamente de lo que producen nacionalmente, ni pueden llevar a cabo todos sus proyectos de desarrollo por su cuenta y riesgo. En este sesgo, es la apertura a los mercados de inversión extranjera y la liberalización de la economía mundial aquello que ha permitido la maximización del progreso en muchas naciones, realidad que no es ajena en Latinoamérica.

Pero esta apertura de la inversión entre estados y empresas o inversores se ha enfocado en la necesidad de proveer un adecuado mecanismo de protección de las inversiones de los parti-

\footnotetext{
42. Redfern, A., y Hunter, M.. Law and Practice of International Commercial arhitration, p. 23.

43. Gonzilezz de Cossto, F., Arbitraje, tercera edición, Editorial Portúa, Mćxico, 2011, p. 75.

44. Cremades, B. y MAdAlena, I., "Procedimientos paralelos en el arbitraje internacional", Revista Internacional de Arbitraje, No. 8, 2008, p. 13.

45. GONZAllez DE Cossio, F., Arbitraje, p. 898.
} 
culares en terceros países, aspecto que ha guardado silencio frente a los riesgos de violación de Derechos Humanos de los pueblos indígenas. Esta afirmación que parece casi una obviedad, adquiere mayor importancia si se consideran las actuales circunstancias y el panorama político desatado en ciertos países, especialmente de América Latina, donde el nivel de protección y de seguridad que se ofrece al inversionista y a los mismos pueblos indígenas han generado múltiples problemas como la politización de los conflictos, costo elevado de los arbitrajes de inversiones, dificultades de los estados para litigar ante árbitros que no conocen la cultura del estado receptor y a veces ni el idioma, etc.

En este contexto, es factible definir dos conceptos entrelazados entre sí: la existencia de un derecho internacional de inversiones que tiene como una de sus herramientas de protección al arbitraje internacional de inversiones.

Si bien no existe un reconocimiento unánime sobre lo que debe entenderse por inversión extranjera ${ }^{46}$, se puede colegir que es el concepto medular que imprime identidad al derecho internacional de inversiones y resulta crucial a los efectos de determinar si las partes han consentido al arbitraje y si el tribunal arbitral es competente en las diferencias entre inversores y esta$\operatorname{dos}^{47}$.

El derecho internacional de las inversiones extranjeras es uno de los temas más candentes del derecho internacional y ha generado mucha controversia ${ }^{48}$, probablemente por ser bastante complejo debido a que involucra áreas de potencial conflicto político en el ámbito internacional, como la tensión creada a raíz de la intención de muchos países en desarrollo de retomar el control de los recursos naturales que habían perdido durante los procesos de conquista y colonización ${ }^{49}$.

46. Mornles VelA, D., "Arbitraje Intemacional de Inversiones: Conflictos en la Aplicación de Clảusulas paraguas", p. 48.

47. Rigo Surfda, A., "La noción de inversión protegida", en Mantilla Scrrano, F. Coordinador, Arbitraje Internacional. Tensiones actuales, Legis/Comitt colombiano de arbitraje, Bogotó, 2007, p. 3.

48. GonzAl,EZ de Cosslo, F., Arbirruje, p. 898. 
Uno de sus aspectos más sensibles es justamente la relación que mantiene con los Derechos Humanos, pues en principio hay una influencia directa en la defensa de los inversionistas, ya que protege el derecho humano de propiedad ${ }^{50}$, pero también se observa un desentendimiento de ciertos actores que, directa o indirectamente, por ejemplo, sufren por la actividad extractiva de las empresas que han contratado con un estado en base a acuerdos de comercio o instrumentos internacionales.

En definitiva, este derecho ${ }^{51}$ surgió ante la necesidad de contar con principios propios que garanticen y promuevan las actividades de los inversionistas extranjeros, ya que el derecho internacional consuetudinario no les brindaba seguridad, empero, floreció de forma fragmentada o aislada del resto de ramas del derecho internacional y ahora se encuentra formado básicamente por una inmensa "red" de tratados de promoción y protección de inversiones ${ }^{52}$ que toma mucho de la llamada lex mercatoria ${ }^{53}$.

49. Morales Vela, D., “Arbitraje Internacional de Inversiones: Conflictos en la Aplicación de Cláusulas paraguas", p. 49.

50. Cabe ensayar una breve diferencia entre los conceptos de derechos humanos y derechos fundamentales, pues los derechos humanos reconocidos en la Constitución se denominan derechos fundamentales. Los derechos fundamentales son aquellos derechos que el poder constituyente, máxima expresión juridica de la soberania popular, ha considerado los más importantes, los seleccionados para gozar del mayor nivel de garantia. Ver Escobar, G., Introducción a la teoria juridica de los Derechos Humanos, Centro de iniciativas de cooperación al desarrollo Universidad de Alcalả, Madrid, 2005, p. 27. En definitiva la expresión derechos fundamentales hace referencia a una categoria de los derectios humanos, a los cuales simplemente se considera más importantes que otros de naturaleza meramente accesoria. o derechos que tienen un carícter intangible, en cuanto no se pueden suspender bajo ninguna circunstancia. Ver FAÚNDIZ. Lede.SMA, H., El Sistema Interamericano de Protecciön de los Derechos Humattos. Aspectos institucionales y procesales, p. 4.

51. "There is no doubt, however, that the current state of the law is characterized by the fact that the international law of foreign investment has become a specialized area of the legal profession and that special courses are offered on the subject matter in universities worldwide. The common usage and parlance in the terminology of international law has always been to single out and to designate distinct fields, such as the "laws of war" or the "law of the sea", whenever the body of rules in any one of such areas has become extensive and dense enough to justify special attention and study. Foreign investment law consists of layers of general international law, of general standards of international economic law, and of distinct rules peculiar to its domain. The study of the field must take into account and turn to all of these three levels of the law". Ver DOLZER, R., y ScuiREuER. C., Principles of International Investment Law; Oxford University Press, Oxford/ New York, 2008, pp. 2-3.

52. FernÁNDEZ MASIÁ, E., "Expropiación indirecta y arbitraje en inversiones extranjeras", Revista Internacional de Arbitraje, No. 7, 2007, p. 14. 
Por último, los defensores del derecho internacional de las inversiones indican que tenderá a crearse y a recrearse en la jurisprudencia de los tribunales arbitrales que se constituyan bajo el sistema CIADI o bajo las reglas UNCITRAL. Además formulan una advertencia muy interesante, pues explican que las culturas jurídicas que se comunican a través del arbitraje deben estar atentas a los brotes de incultura jurídica y de aculturación que no han tardado en aparecer para demeritar ${ }^{54}$ al arbitraje internacional de inversiones y para ensimismar a los regímenes legales en un aislamiento injustificado en un mundo cada vez más interrelacionado ${ }^{55}$. Es decir, se observa que este derecho ha provocado una lucha dogmática, pues por un lado se habla de una rama unificadora que considera a los diversos sistemas jurídicos en torno a la defensa de la inversión, pero por otro lado, no se puede omitir la existencia de ordenamientos jurídicos locales o la misma defensa de derechos como los Derechos Humanos que son transversales a las distintas familias jurídicas y que además se incorporan en los litigios internacionales sobre inversión cuando existen actores como los pueblos indígenas que pueden ser afectados directa o indirectamente.

Como se advierte, esta nueva rama jurídica necesita mecanismos para resolver los distintos conflictos que surgen en su seno, en especial aquellos que provienen de las reclamaciones de un inversor frente al estado receptor a causa de perjuicios sufridos por la inversión. En este sentido, las partes inmiscuidas (estado receptor e inversionista) bien pueden adoptar distintos

53. El derecho internacional ư las inversiones es el producto de una confluencia de tradiciones juridieas expresadas en estándares de protección a la inversión extranjera como son la no discriminaciön, el trato justo y cquitativo, la no confiscación, la cláusula de la nación más favorecida, ci trato nacional, todos ellos oricntados a precautelar el derecho natural a la seguridad juridica, el principio universal de buena fe y el derecho humano fundamental a la propiedad. Estos estándares nacidos de la costumbre y de prácticas inveteradas han sido recogidos en tratados de protección de inversiones y en capituios específicos de los denominados tratados de libre comercio, Ver Neira Orel. Ana, E., "Cultura juridica y protección de inversiones extranjeras", Revista ecuatoriana de Arbitraje, 2009, p. 169.

54. Egerhardt, P., y OLivet, C., Cuando la injusticia es negocio. Cómo las firmas de abogados, àrbitres $y$ financiadores alimentan el antge del arbitraje de inversiones, traducción de Bcatriz MARTINE. Corporate Europe Observatory y Transnational Institutc, Brusclas/Amsterdam, 2012. Disponible en [http://www.tni.org/sites/www.tni,org/files/download/cuando la_injusticia_es_negocio-web.pdf], (Pa. gina visitada el 8 de julio de 2014).

55. Neira Orellana, E., "Cultura juridica y protección de inversiones extranjeras", p. 170. 
mecanismos de resolución de conflictos: procedimientos ante los tribunales nacionales internos del estado, conciliación, mediación, arbitraje o protección diplomática que puede transformarse en una controversia interestatal que enfrente al estado receptor de la inversión y al estado de procedencia del inversor ${ }^{56}$.

Si las partes escogen el arbitraje para zanjar las diferencias descritas ut supra, entonces, se suele hablar de arbitraje de inversiones ${ }^{57}$, aunque éste puede también recibir otras denominaciones como arbitraje inversor-estado, arbitraje mixto ${ }^{58}$, arbitraje transnacional unilateral o arbitraje sin vínculo contractual ${ }^{59}$.

Así las cosas se puede colegir que la voluntad de someterse a arbitraje de inversiones puede surgir no solamente de un contrato, sino que proviene con más fuerza de un AEI, de un TBI o de la ratificación de un instrumento internacional como el Convenio CIADI por parte del estado receptor y el estado del inversor $^{60}$.

Es decir, un estado se encuentra obligado a someterse a un proceso arbitral como consecuencia de su propia voluntad soberana, toda vez que ha consentido someter futuras disputas en una sede arbitral. En concreto, la fuente de todo arbitraje es su voluntad expresada en las fuentes ya descritas, esto es, en las cláusulas de un tratado de inversión, en convenios individuales celebrados directamente con los inversores o en las mismas leyes naciona$\operatorname{les}^{61}$.

56. Zambrana Tévar, N., La deterninación del derccho aplicable al fondo cn el arbitraje de inversiones, Aranzadi Thomson Reuters, The global law collection, Navarra, 2010, p. 25.

57. El arbitraje de inversiones conoce aquellos conflictos surgidos entre sujetos de derecho privado - inversionistas-y estados investidos de potestad soberana y es la expresión de una determinada cultura juridica porque reflcja el ideal de justicia en la protección del derecho humano de propiedad, del principio dela seguridad juridica y de la buena fe en las decisiones qute adopta el poder püblico con relación a una inversión extranjera. Adicionalmente, plantea un encuentro entre culturas juridicas diversas. Ver Netra ORELLANA, E., "Cultura juridica y protección de inversiones extranjeras", pp. 151 y 152.

58. El arbitraje es mixto cuando se presenta entre estados soberanos, por un lado, y entes privados/particulares, por el otro. Es aqui donde se ubica el arbitraje del CIADI. Ver GonzAlez de Cosslo, F., Arhttraje, p. 916.

59. Zambrana TEVAR, N., La determinación del derecho aplicable al fondo en el arbitruje de inversiones, p. 26.

60. Las denominadas cläusulas parnguas mucstran esta realidad. 
Sin embargo, un problema que ha permanecido en muy bajo perfil ha sido la interacción, relación, interferencia o colisión entre este derecho internacional de las inversiones y el derecho internacional de los Derechos Humanos ${ }^{62}$, donde la defensa de los derechos de los pueblos indígenas no puede ser ocultada, en especial el derecho a la auto determinación que forma parte de las normas de Ius Cogens así como sus derechos colectivos territoriales ${ }^{63}$.

Sobre esta relación nada pacífica, el jurista Eduardo SILVA RoMERO $^{64}$, cita una frase fulminante de Philippe KAHN, donde manifiesta la reciente o poca preocupación por esta realidad: "On constate que le problème est abordé avec une discrétion qui frise le silence" y no sorprende ya que se vive en un mundo en el cual los intereses económicos y comerciales tienden a prevalecer sobre los derechos que no entran en esta realidad o tienen otras preferencias o valores.

El problema medular es que el mismo artículo 17 de la Declaración Universal de los derechos del hombre ${ }^{65}$ colisiona con otros derechos que tanto el estado como las mismas empresas in-

61. En la actualidad el modelo CIADI es el que más arbitrajes de inversión administra, pues hasta el 11 de abril de 2014, ya 159 estados han fimado el Convenio sobre Arreglo de Diferencias Relativas a Inversiones enire Estados y Nacionales de Otros Estudos. Ver Lista de estados contratantes y signatarios del Convenio, (https//icsid worldbank, org/ICSID/FrontServlet?requestType=CasesRH\&actionVal= Showhome\&pageName-MemberStates_Home], (página visitada el 10 de julio de 2014).

62. La question qui se pose aujourd'hui est celle d'établir quelles corrélations existent entre le droit international des investissements el les autres domaines du droit international, afin de tenir compte des va* leurs non marchandes en général el de la protection des drojts de l'homme en particulier. Jusqu'à présent la question des rapports entre droit international des investissements et droits de l'homme n'a pas été abordéc de façon systématique, mème si le problème en soi n'est pas nauveau, puisqu'il s'est dẻjà posé à plusieurs reprises à partir des années soixante et soixante-dix. Ver LIBERTI, L. "Investissements et droits de I homme", V1I Global Forum on International Investment, OECD, 2008, en [http:/www.oecd.org/investment/globalforum/40306263.pdf], (Pigina visitada el 10 de julio de 2014).

63. Una forma de clasificar a los derechos humanos puede ser en base a su condición indivielual o colectiva. En este sentido, el uerecho a la autodeterminación de los pueblos es uno de corte colectivo. Hoy resulta claro que existe un nuevo escenario, no necesariamente liberal, que ha trascendido la tradicional visión que los derechos humanos son solamente individuales.

64. Silva Romero, E., El mito del carácter ilimitado del derecho a la propiedad de las inversiones, p. I, cn [http:/www.dechert,com/files/Publication/523fo631-58d4-4a36-a2af-08c94bee-701c/Presentation/PublicutionAttachment/b2ded $1 \mathrm{fa}-40$ Z-4dB-able-005fda82cebc/ESR\%20-\%20EJ\%20mito\%20del\%20 caracter $\% 20$ ilimitado $\% 20$ del $\% 20$ derecho $\% 20 \mathrm{a} \% 201 \mathrm{a} \% 20$ propiedad $\% 20$ de $\% 20 \mid$ os $\% 20$ inversionistas PDF], (Página visitada el 10 de julio de 2014).

65. "Articulo 17: 1. Toda persona tiene derecho a la propiedad, individual y colectivamente. 2. Nadie seri privado arbitrariamente de su propicdad". 
versoras deben respetar, tal es el caso del derecho al medio ambiente, derecho al agua y, por supuesto, los derechos colectivos de los pueblos indígenas ${ }^{66}$. Todavía el problema es más complejo cuando colisionan diversos instrumentos internacionales que protegen diferentes derechos fundamentales.

En este sentido, existen dos colisiones que preocupan, tanto más que probablemente los árbitros, en muchos casos, tendrán la obligación de analizarlas y decidir en base a lo más justo y equilibrado no solamente para los inversores y el estado sino para terceros que pueden ser afectados con esta realidad espinosa ${ }^{67}$, en especial con el irrespeto de derechos fundamentales en contra de los pueblos y nacionales indígenas que van más allá de los instrumentos internacionales de inversión y sus contratos. En esta línea, las colisiones concretas son: a) medidas estatales previas que inobservan derechos colectivos pero que sirven de base para iniciar actividades extractivas con empresas que ejecutan contratos y no ponen reparo alguno en la falta de respeto de los derechos fundamentales de los pueblos indígenas, así por ejemplo la explotación de recursos naturales en una zona donde no se ha consultado a los pueblos $y$, sin embargo, se aprueban los trámites administrativos y contractuales, b) Una vez iniciadas las actividades extractivas, el estado toma medidas en defensa de los derechos fundamentales de los pueblos indigenas, aspecto que puede considerarse fuerza mayor o expropiación.

El reto es el manejo de la ponderación y proporcionalidad como elementos de interpretación de los árbitros de inversiones,

66. Antes de la integralidad de los Derechos Humanos, se solia hablar de Derechos humanos de tercera generación que se orientan a defender y obtener la solidaridad y que busean proteger a sujetos no solamente individuales como los pueblos indigenas sino que además protegen conceptos vitales para la existencia del ser humano como el desarrollo, la paz, el medio ambiente sano, elc.

67. Precisamente este es el reto que los árbitros deben enfrentar, pues aplican las normas establecidas por las partes, ya sea en forma contractual, convencional e inclusive legislativa, empero, exislen disposiciones de obligatorio cumplimiento y que se encuentran por encima de las disposiciones legales o convencionales de inversiones porque constituyen ius cogens. En otras palabrus, al ser ciertas normas de Derechos Humanos ratificadas por ta mayoria de paises y al ser una de las partes los estados, el principio dispositivo sufre una relatividad, pues al aceptarlo a raja tabla propiciaria una tendencia contraria a los Derechos Humanos de los pueblos indigenas, ya que los árbitros podrian esgrimir que esos derechos existen pero al no ser presentados por las partes no tienen competencia para aplicarlos. Me parece que el principio iura novit curia bien podria ser aplicado por los tribunales. 
pues muchas veces en la relación estado-inversor bien pueden aparecer aspectos relacionados con los derechos de terceros que no necesariamente fueron considerados para suscribir un convenio arbitral o cuando un instrumento internacional fue aprobado ni siquiera los consideraron, aunque, no obstante, pueden ser afectados con sus laudos o interpretaciones.

La relación entre los derechos y obligaciones generadas por los tratados de inversión y otros derechos y obligaciones que surgen bajo instrumentos del derecho consuetudinario internacional pueden únicamente acercarse mediante una integración sistemática que no es más que un proceso de razonamiento que permite hacerlos aparecer como elementos de un todo coherente y sustancial $^{68}$.

Por eso precisamente resulta importante considerar que el campo de los Derechos Humanos constituye un régimen especializado que impacta o afecta a todos los otros elementos o ramas del derecho internacional y si es así no será únicamente otro sistema especializado aislado sino se convertirá en uno que imprima unidad a todos los demás ${ }^{69}$.

Para comprender la importancia de la defensa de los Derechos Humanos en el arbitraje resulta necesario entender la complejidad del dramatis personae, o sea, de los actores que están implicados en las inversiones internacionales, en especial, en el tema de la industria extractiva.

Hay cuatro clases de actores que intervienen en el derecho internacional de inversiones: los gobiernos tanto de países desarrollados como en vías de desarrollo; el sector privado interna-

68. International Law Commission. Fragmentation of International Law: Difficulfies arising fmm the Di. versification and Expansion of International Law: Report of the Study Group of the Internationai Law Commission. Un Doc A/CN.4/L682, 13 April 2006. Paragraph 414.

69. FRY J,.p. 123. There is a possibility that the field of human rights be an "extra-special type of specialized regime that impacts all aspects of international baw, and should not be seen as just another specialized body of law that other specialized bodies might use to reinterpret their own rules in its light, but is one that requires other specialized bodies to be reinterpreted in its light." If that would be the case, the existence of such an influential specialized body of intemational law itself would be an evidence of international law's unity. 
cional; la clase media internacional o sociedad civil; y los guardianes o contralores oficiales del sistema legal internacional ${ }^{70}$, aunque también, conforme a nuestra explicación anterior, debería agregarse en este cuadro de actores a aquellos grupos que son afectados por las actividades de los inversionistas y del mismo estado, en este caso, uno de ellos son los pueblos indígenas que sin ser necesariamente considerados en el convenio arbitral o en los TBI son, empero, muchas veces directamente afectados como terceras partes o terceros no signatarios ${ }^{71}$, pues reciben las consecuencias o impactos del extractivismo, ya sea por el irrespeto de las normas de Derechos Humanos, ya sea por los impactos negativos producto de la industria exractiva.

Al respecto, un punto aparte merecen dos aspectos esenciales: 1) las obligaciones de los estados en materia de protección de los Derechos Humanos y su interacción con las inversiones extranjeras, y 2) las obligaciones internacionales de los inversionistas en materia de Derechos Humanos y la eventual apreciación de la licitud de su conducta dentro del contexto arbitral estado e inversor.

En este tema, precisamente los árbitros de inversiones, en los casos concretos que se someten a su juzgamiento, en especial en aquellos donde apareciere el tema de los Derechos Colectivos de los pueblos indígenas, deberían convertirse en los garantes del respeto del derecho y de los valores fundamentales que están encargados de hacer prevalecer y no deben transformarse únicamente en intérpretes de instrumentos internacionales que beneficien a los inversores o a los estados, pues podrían en caso de insistir en este unilateralismo convertirse en cómplices de una inobservancia de derechos humanos ${ }^{72}$.

70. REISMAN, W. M., "Reflections on economic development, national sovereignty and intemational arbitration", en Mantul.. Serrano, F. Coordinador, Arbitraje Internacional. Tensiones actuales, Legis/Comité colombiano de arbitraje, Bogotá, 2007, p. xvii.

71. The terms "third party" and "non signatory" are regulariy used interchangeably. However, they have different measings: third party is a wide term referring to any party that is not designeted in an arbitration clause. Ver Brekoulakis, S., Third parties in international contercial arbitration, Oxford, 2010, p. 2.

72. LIBERTI, L., "Investissements et droits de l'homme", p. 851. 
Además se insiste en el hecho que los árbitros no pueden dejar de usar las normas imperativas de derecho internacional o ius cogens ${ }^{73}$, sobre todo, cuando deben ponderar el uso de instrumentos internacionales que colisionan en los conflictos de inversiones o al menos, con el objetivo de proteger los Derechos Humanos de los pueblos indígenas nada impide, al menos es mi criterio particular, que el tribunal arbitral pueda remitir los casos a los operadores competentes que pueden establecer la responsabilidad internacional de los estados o de otros sujetos internacionales o sencillamente aplicar el contenido de las sentencias de las Cortes de Derechos Humanos que son vinculantes.

En el primer aspecto, gracias a la jurisprudencia de la CorteIDH se ha superado el hecho de que los pueblos indígenas no son sujetos de derecho internacional ${ }^{74}$ y se ha permitido que comunidades nativas puedan reclamar el cumplimiento de derechos colectivos territoriales, tal es el caso Sarayaku vs Ecuador y otros similares ${ }^{75}$. La consecuencia inmediata es que los pueblos y nacionalidades indígenas tienen plena subjetividad internacional $\mathrm{y}$, por ende, pueden presentarse ante las cortes internacionales, no tendiendo porque ser la excepción su presencia en los tribunales arbitrales.

73. Este ius cogens se refiere a los principios del derecho intemacional considerados de la mayor importancia, gozando por ello de preferencia y prioridad sobre otros principios de derecho basado en los tratados y el derecho consuetudinario. En otras palabras, las normas imperativas harán caso omișo e invalidarán otros principios del derecho intemacional. En consecuencia, los estados no pueden plantear un tratado que presente conflicto con una norma imperativa reconocida-como exterminar a otro pucblo o población de otro estado, por ejemplo-. Existen pocos principios de derecho internacional a los que se ha concedido la condición de ius cogens. Son cjemplos de cllo la prohibición de genocidio y de la esclavitud y el principio de libre determinación. Ver MAckaY, F., Los derechos de los pueblos indigenas en el sistema internucional, APRODEH/FIDH, Lima, 1999, p. 50.

74. In 1945 the priority was to safeguard individual rights. But since 1966 the International Covenants (on civil and political rights and on economic, social and cultural rights) introduced a collective dimension to human rights, establishing in their first article that the fulfilment of collective rights of peoples is a pre-condition for the effective enjoyment of individual human rights. Despite the fact that intemational law recognizes certain rights to peoples and minorities, however, it does not allow them to claim these rights before international bodies. Groups of individuals thus do not appear as the holders but rather as the adressees of these rights - they are, in this sense, objeets of intemational law. Ver Crawfond, J., PelLet, A., and OLLeson, S., The Law of International Responsability, Oxford, 2010, p. 994.

75. Existen también algunas sentencias de la CorteIDH que tratan, desde varios ángulos, los derechos de tos pueblos indigenas sobre los recursos naturales, tal es el caso de Comunidad Saramaka Vs. Suriname. Comunidad Mayugna (Sumo) dwas Tingni is. Nicaragna. Commidad indigena Yahje Axa I's. Para-

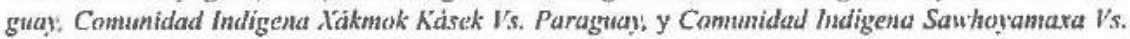
Paragutu: 
En cambio, en la segunda realidad se ha advertido que el arbitraje ha sido considerado como una herramienta efectiva y, por ello, ha sido usada por la mismísima $\mathrm{CIDH}$, pues en la sentencia emitida en el caso Chaparro Álvarez y Lapo Íniguez vs. Ecuador ${ }^{76}$ se obligó a las partes procesales involucradas a resolver mediante arbitraje la cuantificación del daño material e indemnización ${ }^{77}$. En este sentido, este caso marca un hito tanto en la defensa de nuevos derechos como el aparecimiento de nuevos sujetos ante la Corte Interamericana, ya que se resuelve sobre temas patrimoniales que afectan a los derechos de las personas jurídicas, cuando la idea fuerza ha sido que las personas naturales son las únicas titulares de los derechos convencionales, tema que corrobora, sin

76. Caso Chaparno Alvarez y Lapo hïguez is Ecuador, sentencia de 21 de noviembre de 2007, Excepciones preliminares, fondo, reparaciones y costas. También revisar la sentencia de 26 de noviembre de 2008, interpretación de la sentencio de excepeiones preliminares, fondo, reparaciones y costas. Por la importaneia citamos las partes pertinentes de dicha sentencia, asi la CortelDH dispone que: "13. El Estado y cl scñor Juan Carlos Chaparro Álvarez deberín somelerse a un proceso arbitral para fijar las cantidades correspondientes a daño material, en los términos de los párrafos 232 y $233 \mathrm{de}$ esta Sentencia". Los párrafos rezan: "232. Por lo anterior y dada la complejidad que supone la determinación de valores mercantiles de una cmpresa, los cuales pueden incluir, inter alia, el patrimonio, situaciỏn financiera, inversiones de capital, bienes y sus valores, movilizado y circulante, flujos operacionales, expectativas de mercado y demás, esta Corte considera que deberí ser un tribunal de arbitraje el que determine el porcentaje de pérdidas que sufrió el señor Chaparro como consecuencia de la aprehensión y depósito de la fäbrica Plumavit por parte del Estado. Sin perjuicio de lo anterior, la Corte tienc en cuenta que dicha fabrica habia operado por varios años y que al momento de los hechos habia recibido algunos préstamos para mejorar su productividad, razones por las cuales fija en cquidad el monto de US\$150.000,00 (ciento cincuenta mil dólares de los Estados Unidos de América) por este concepto. En caso de que el monto determinado en el procedimiento arbitral sea mayor que lo ordenado por la Corte en esta Sentencia, el Estado podra descontar a la victima la cantidad fijada en equidad por este Tribunal. Si el monto determinado en el procedimiento de arbitraje es menor, la vietima conservará los US\$150.000,00 (ciento cincuenta mil dólares de los Estados Unidos de América) fijados en esta Sentencia. La cantidad establecida por esta Corte deberá ser entregada al señor Chaparro en un p̧lazo no mayor a un año contado a partir de la notifieación de la presente Sentencia. 233. El procedimiento arbitral señalado en cl párrafo anterior deberá ser de carácter independiente, llevarse a cabo en la ciudad en la que resida el señor Chaparro y conforme a la legislación interna aplicable en materia de arbitraje, siempre y cuando no controvierta lo estipulado en esta Sentencia. El procedimiento deberá iniciarse dentro de los seis meses contados a partir de la notificación de la presente Sentencia. El tribunal de arbitraje estará integrado por tres árbitros. El Estado y cl señor Chaparro elegirán cada uno a un árbitro. El tercer árbitro será elegido de común acuerdo entre el Es. tado y el señor Chaparro. Si en el plazo de dos meses contado a partir de la notificación de la presente Sentencia las partes no llegan a un acuerdo, el terecr árbitro será elegido de común acuerdo por el àrbitro elegido por el Estado y el elegido por el scnoor Chaparro. Si los dos árbitros no llegaran a un acuertio dentro de los dos meses siguientes, el Estado y el señor Chaparro o sus representantes deberán presentar a esta Corte una terna de no menos de dos y no más de tres candidatos. La Corte decidirá el tercer árbitro de entre los candidatos propuestos por las partes. La cantidad decidida por el tribunal de arbitraje deberá ser entregada al señor Chaparro en un plazo no mayor de un año contado desde la notificación de la decisión del tribunal arbitral".

77. Gaceta Arbitral, Garcia H., coordinación y edición general, Cámara de Comercio Ecuatoriana Americana (AMCHAM) y Universidad San Francisco de Quito, No. 1, 2013, pp. 291-333. 
duda, la tesis de la defensa de los derechos colectivos de los pueblos indígenas en sede arbitral.

En definitiva, el tribunal arbitral, siempre en los casos concretos de su conocimiento, deberá evitar que se vulneren los derechos colectivos de los pueblos indígenas, en especial cuando surgen en el litigio internacional, y si se advirtiere esta situación, siguiendo la experiencia descrita ut stupra, pero invirtiendo el orden, el árbitro tendría dos posibilidades, ya sea fallar aplicando ius cogents, ya sea remitir a las cortes competentes para que resuelvan el tema de los Derechos Humanos o los organismos competentes ayuden a interpretar la aplicación de los instrumentos internacionales de Derechos Humanos.

Sobre el ius cogens se advierte que comprende un conjunto de normas imperativas que son exigibles no solo a los estados sino a todos los sujetos de derecho internacional, constituyendo su inobservancia actos objetivamente ilegales ${ }^{78}$. En este sentido, los derechos colectivos como aquellos de propiedad de los pueblos y nacionalidades indígenas, gracias a los pronunciamientos jurisprudenciales de la CorteIDH, se encuentran en el camino de la consolidación del derecho a la autodeterminación de los pueblos por la inclusión de nuevos elementos y, por ello, forman parte del ius cogens.

Es decir, la propiedad colectiva es un elemento del derecho a la autodeterminación y es necesario que se comprenda esta compleja realidad en la decisión de los tribunales arbitrales que deben equilibrar los intereses en juego y no responder únicamente por el estado o por los inversionistas.

Esta realidad nos conduce a varios retos, pero uno que resulta vital es la restauración o cambio profundo del régimen internacional de inversiones, pues urge que los TBI sean renegociados para imponer obligaciones de Derechos Humanos en la parte de los inversionistas -debe dejar de ser soft law - evi-

78. Voto concurrente del juez A.A. Cancado Trindade. Caso del Pueblo indigena Sarayaku vs. Ecuador. Medida provisional. Resolución de 17 de junio de 2005, párrafo 23. 
tando así los acuerdos unilaterales del tratado o contrato y entonces los tribunales arbitrales también van a dar importancia al ius cogens e incluso quedaría abierta la posibilidad de incluir una apelación mediante la cual se resuelvan temas como el respeto de los derechos de los pueblos indígenas o la determinación de los beneficios o utilidades de la inversión a la que tienen también pleno derecho, pero que desafortunadamente el estado y las mismas empresas, apropiándose de estos conceptos, los han remitido a un segundo plano.

Sin duda alguna, un tema que debe ser resuelto es el hecho que el propio estado que ha suscrito y concluido los instrumentos internacionales de inversión lo ha efectuado sin tener en cuenta los derechos que el mismo también ha reconocido a los pueblos y nacionalidades indígenas como derechos colectivos e incluso los mismos instrumentos internacionales que amparan a dichos pueblos.

La consigna será, entonces, que el estado deberá unificar sus criterios de protección de los pueblos indígenas tanto en la esfera constitucional como en el terreno internacional, únicamente así los derechos colectivos recobrarán su eficacia y serán respetados y defendidos por todos los operadores nacionales o internacionales, donde se incluyen los tribunales arbitrales de inversiones.

\section{ConClusiones}

1. El derecho a la autodeterminación de los pueblos indígenas es un derecho que puede ser reclamado ante los tribunales arbitrales, pues al ser ius cogens es de obligatoria aplicación para todos los operadores judiciales y arbitrales. En este sentido, se podría contar con un espacio para considerar los Derechos Humanos de los pueblos indígenas en los conflictos suscitados entre el estado y los empresarios siempre y cuando surja el conflicto dentro del litigio estado-inversionista. 
2. Los tribunales arbitrales internacionales o los mismos tribunales nacionales cuando consideren que están en juego los derechos colectivos de los pueblos indígenas son competentes para resolver los conflictos puestos a su consideración, pero su intervención deberá considerar el Derecho internacional de los Derechos Humanos como un elemento integrador del Derecho Internacional.

3. Gracias al ius cogens los tribunales arbitrales pueden permitir la intervención de los representantes de estos pueblos indigenas en los procesos arbitrales que los afectan a causa de la extracción de recursos naturales, aunque también la aceptación de los amicus curiae puede ser un instrumento que permita a los árbitros conocer aspectos de los Derechos Humanos que probablemente no comprendían.

4. El Derecho Internacional de Inversiones debe preocuparse no únicamente por la protección de los inversionistas sino que debe analizar y amparar a los grupos que como los pueblos indígenas pueden ser afectados por las actividades pactadas por el estado y la empresa. 